\title{
PROPOSTA DE IMPLEMENTAÇÃO DE MELHORIA DA ÁREA DE MARKETING: ESTUDO DE CASO NA EMPRESA DE COLETA DE RESÍDUOS J.A OLIVEIRA PEIXOTO - ME EM MANAUS
}

\section{ARTIGO ORIGINAL}

OLIVA, Luiz Paulo de Verçosa 1, OLIVA, Paulo Francisco Paiva de 2, GLUCK, Wilhelm Braz ${ }^{3}$, ROBERTO, José Carlos Alves ${ }^{4}$

OLIVA, Luiz Paulo de Verçosa. Et al. Proposta de implementação de melhoria da área de marketing: Estudo de caso na empresa de coleta de resíduos J.A Oliveira Peixoto - ME em Manaus. Revista Científica Multidisciplinar Núcleo do Conhecimento. Ano 06, Ed. 05, Vol. 07, pp. 139-157. Maio de 2021. ISSN: 24480959, Link de acesso:

https://www.nucleodoconhecimento.com.br/administracao/melhoria-da-area, DOI: 10.32749/nucleodoconhecimento.com.br/administracao/melhoria-da-area

\section{RESUMO}

O presente trabalho tem como objetivo elaborar um plano de implantação de melhoria da área de Marketing utilizando a ferramenta 5 w2h dentro da Empresa J.A OLIVEIRA PEIXOTO- ME. Através desta ferramenta, encontramos como ponto crítico a divulgação da marca da empresa. Com as análises feitas e os resultados

\footnotetext{
${ }^{1}$ Graduando do curso de Administração.

${ }^{2}$ Graduando do curso de Administração.

${ }^{3}$ Graduando do curso de Administração.

${ }^{4}$ Orientador. Mestrado profissional em Engenharia de produção. Especialização em Gestão em Logística empresarial. Graduação em Administração com Ênfase em Marketing.
}

$\mathrm{RC}: 84989$

Disponível em: https://www.nucleodoconhecimento.com.br/administracao/melhoria-da-area 
adquiridos, demos início a implantação de melhorias na área mais crítica identificada. As implantações de melhorias levaram em consideração a importância nos treinamentos de funcionários, implantação de ferramentas para melhoria do atendimento e melhoria dos preços e promoções tanto nos aluguéis dos equipamentos como nos serviços prestados aos clientes. Com cinco ações interventivas, observamos uma melhora na imagem da marca para os clientes e possíveis parceiros, que poderão contribuir com a empresa em seu ramo de negócios, melhorando, assim, os lucros da empresa em relação às mudanças. A melhoria do marketing da empresa, com estas metas sendo implantadas, demonstra o quanto a visibilidade da marca diante do mercado de Coleta de resíduos pode melhorar, trazendo lucros e benefícios dentro e fora da empresa. Concluímos que todas as etapas feitas, desde a pesquisa para encontrar os problemas até sua análise e implantação, para assim montarmos um melhor modo de ação interventiva com uma visão futura de lucratividade e claro que status mediante aos clientes que irão tornar a marca da empresa uma marca conhecida por suas qualidades no serviço, atendimento e até mesmo rapidez, mostrando assim, que de fato o marketing usado de forma adequada e certa pode, e é capaz de fazer uma empresa como J.A OLIVEIRA PEIXOTO- ME melhorar e mudar seus valores para melhor atendimento aos clientes e seus colaboradores.

Palavras-chave: marketing, preços, promoções, implantação.

\section{INTRODUÇÃO}

Em meio a evolução do mundo, a produção de coleta de resíduos sólidos vem aumentando e causando várias melhorias ao ambiente e à saúde pública, todas as etapas da gestão dos resíduos sólidos, que englobam desde a sua geração até sua disposição final, exigem soluções conjuntas entre a sociedade e aqueles a governam, haja visto que o volume dos resíduos cresce em proporções geométricas, enquanto a dissolução para a questão aumenta substancialmente.

RC: 84989

Disponível em: https://www.nucleodoconhecimento.com.br/administracao/melhoria-da-area 
Neste cenário atual de mercado, vimos que globalizado e concorrência acirrada, a comunicação bem-focada e embasada, pode ser o diferencial para que as empresas possam ampliar ou redirecionar seus negócios ou, apenas, continuarem competitivas. O aprendizado nas organizações vem tendo muita importância e sendo explorado como diferencial diante de um mercado tão concorrido.

Desta forma decidimos iniciar práticas de melhorias mediante ao problema no qual foi analisado como o de maior dificuldade para dentro da empresa, que foi a falta de divulgação e marketing mediante de sua marca, para que isso acontecesse desenvolvemos uma análise com base na ferramenta de qualidade que nos mostrou problemas nos quais fazemos correções para não somente alavancar vendas, mas, também para proporcionar melhorias na divulgação da marca da empresa no qual exerce um não somente um bom empenho sobre coleta de reciclagem, mas também na contribuição de melhoria ao meio ambiente.

Com esta implantação de melhoria, vamos perceber que a companhia não apenas teve sua marca divulgada, mas também suas ações mediante ao mercado de coleta de resíduos sólidos no que proporciona uma posição de prestígio diante dos clientes com o atendimento é garantida e não somente isso, mas, com o feedback e com sua rapidez de atendimento e entrega saberemos onde poderemos melhorar para satisfazê-los.

\section{FUNDAMENTAÇÃO TEÓRICA}

A revisão bibliográfica se justifica por reunir as fontes teóricas de onde foram retiradas as bases de conceitos e teorias do artigo, e com isso possui um referencial sólido para se desenvolver o tema do trabalho.

RC: 84989

Disponível em: https://www.nucleodoconhecimento.com.br/administracao/melhoria-da-area 
Segundo Gil (2017), define a análise bibliográfica, é a teoria de base para o projeto, consiste em verificar a existência e usando conhecimentos prévios do autor fundidos aos conhecimentos.

Esta etapa de revisão é valiosa para dar ênfase no conteúdo que está sendo desenvolvido com bases sólidas de reconhecimento em pesquisas já renomadas de autores especialistas no assunto, relatando em detalhes a aplicação do artigo.

\section{MARKETING E ALGUNS CONCEITOS}

O Marketing passou a ser uma ferramenta de uso consideravelmente utilizada no gerenciamento da administração, e seus benefícios e conceitos vem se reformulando e evoluindo junto com o desenvolvimento do próprio comércio e o comportamento dos clientes.

A evolução do marketing deve ser compreendida como um método de gerenciamento e as relações de troca entre as empresas, consumidores, fornecedores, intermediários e os outros públicos da rede administrativa, ou seja, o marketing é uma ferramenta de negócios, apropriando-se do conhecimento de seus clientes para a criação de produtos e o engajamento do mesmo no mercado.

O marketing se tornou o instrumento que cria mercados de uma forma que gera relacionamentos e vínculos, trazendo benefício a todos que estão dispostos a trocarem informações.

Tornou-se uma obra, onde os métodos utilizados são de concordância com cada competência de seus usuários, permitindo que a troca de conhecimento sejam cumpridas da melhor forma possível. Podemos observar o ato ou efeito do marketing através de algumas definições:

O marketing de forma mais simplificada pode ser compreendido como um agrupamento de técnicas e métodos que são utilizados ao

RC: 84989

Disponível em: https://www.nucleodoconhecimento.com.br/administracao/melhoria-da-area 
estudo das necessidades dos mercados e seus principais componentes, clientes, desenvolvimento de produtos, vendas e no desenvolvimento da imagem das empresas. (KOTLER $E$ ARMSTRONG, 2015, p. 75)

\subsection{EVOLUÇÃO DO MARKETING E A CHEGADA DO MARKETING}

\section{0}

Embora seja difícil especificar quando surgiu o marketing, é consenso entre muitos estudiosos que a Revolução Industrial transformou a forma de praticar essa atividade.

Kawamura (2015), após a mudança abrupta industrial, tudo que se produzia se vendia, com a demanda superior que a ofertada, as organizações não estavam muito preocupadas com o bom padrão do que era vendido e nem sequer com a opinião dos seus compradores. Esse foi o cenário onde o marketing se firmava, a preocupação era produzir.

Durante o início, em meio a Era da Informática, os procedimentos de troca e venda não são mais simples. Os clientes possuem muito mais informação, podendo assim assimilar um produto com o outro pois a mais variedade de mercadorias no mercado, logo o marketing parou de ser sobre o produto e tornou-se, como o consumidor se sente sobre o que está comprando.

É nesse momento que o profissional no marketing começa a aparecer para ganhar a simpatia e a apreciação do consumidor, pois os compradores estão em um melhor cenário e possuem desejos e vontades que precisam ser atendidas. Nesse momento e que os consumidores passam a ser tratados como reis, momento que surge o Marketing focado no consumidor 2.0, os clientes decidem o que querem, mas ainda não possuem a noção das manobras de marketing que estão sendo feitas para manipulá-los a comprar (SEIFRIED, 2014)

RC: 84989

Disponível em: https://www.nucleodoconhecimento.com.br/administracao/melhoria-da-area 
Para Santos (2014), o marketing 2.0 fica pautado na necessidade do comprador e para entenderem elas, surge a segmentação de mercado, onde o papel dessa tarefa é delimitar grupos de consumidores, com perfis e interesses em comum, para que se possa encontrar o consumidor alvo em que será trabalhada as estratégias.

O mundo muda e se torna globalizado com a chegada da internet, com esse estrondo de informação nasce o marketing 3.0, é o momento em que as instituições mudam a abordagem direcionada ao cliente/ consumidor para uma abordagem direcionada ao ser humano. Pautada nessa abordagem que as identificações devem assumir traços humanos, as empresas passam a desenvolver valores e princípios e deram início a apoiar causas humanas e ambientais, refletindo a sua humanidade e preocupação com o planeta.

De acordo com Augusto (2016), os consumidores não quererem apenas comprar a mercadoria e usá-lo, eles buscam marcas que assumam compromissos com a humanidade.

Como o marketing surge na era da internet é o 3.0, o marketing 4.0 vem sendo governado pela economia digital, na atualidade tudo vem sendo direcionado pela conectividade, pesquisa, compra, estudar, conversar, vender, se informar, para realizar tudo isso utilizamos a internet.

Logo o consumidor não se prende mais a um único meio de diálogo para encontrar o conhecimento que deseja, a internet lhe traz uma variedade de ferramentas, onde o mesmo pode acessar várias páginas, de diversas fontes até encontrar o conhecimento que deseja (MONTEIRO; BARRETO, 2017, p. 104)

Com toda essa pluralidade de mídias o marketing 4.0 vem para revolucionar não apenas criando uma página no Instagram e tendo milhões de seguidores, mas saber usar de forma excelente suas ferramentas de marketing para proporcionar ao comprador uma experiência marcante que o fidelize.

RC: 84989

Disponível em: https://www.nucleodoconhecimento.com.br/administracao/melhoria-da-area 
Kotler (2017, p. 75$)$, precisa se criar uma lealdade do comprador com a marca, dessa forma o objetivo do marketing é assegurar uma relação forte entre o comprador e a marca ao ponto deste se tornar um protetor da marca.

Os profissionais de marketing estão empenhados a fazer com que os consumidores não comprem apenas um produto da marca, mas que tenham uma relação de compra a longo prazo.

\subsection{ESTRATÉGIAS DE MARKETING PARA EMPRESAS DE RESÍDUOS SÓLIDOS}

Com a globalização e a era da internet, o mundo passou a preocupar-se muito mais com o meio ambiente que o cerca, passaram a entender que "proteger o meio ambiente é proteger a qualidade de vida" (PRADO, 2017, p. 5)

Através desse ideal que se desperta o entendimento de uma lei constitucional que garante a preservação ambiental entendendo sua grande importância para a humanidade.

Conforme o Art. $225^{\circ}$, um ambiente saudável e preservado é uma norma fundamental, declarando assim que toda a sociedade brasileira tem garantido a um meio ambiente preservado, sendo visto como um bem de uso coletivo para a sociedade.

De acordo com Gollo et al. (2019), a partir daí foi apontado e com a evolução do Marketing as empresas de resíduos sólidos através de um bom trabalho de marketing elas podem faturar muito mais, o trabalho com o marketing deve fluir com objetivos organizacionais e trabalho em equipe para colher resultados satisfatórios para a companhia.

RC: 84989

Disponível em: https://www.nucleodoconhecimento.com.br/administracao/melhoria-da-area 
Segundo as organizações que trabalham com coleta de resíduos sólidos, devem utilizar em sua propaganda a proposta que ajude o consumidor a notar a grande importância de adquirir seus serviços, que atuam de forma correta, na retirada dos resíduos sólidos.

Se faz necessário que durante sua campanha de Marketing a empresa utilize uma comunicação ecológica, sobre qual a necessidade e importância de os clientes conseguirem seus produtos, fazendo com que o comprador esteja sempre atendo as vantagens de conseguir um serviço/produto verde, essa ideia não se perca na próxima aquisição.

\subsection{W2H}

A $5 \mathrm{~W} 2 \mathrm{H}$ é uma ferramenta de gestão empregada no planejamento estratégico de empresas, partindo de um contexto para arrumar as atuações e orientar o que será feito para conquistá-la, por este motivo, por quem, como, quando e onde será feito, além de prever quanto isso valerá, em geral proposta na forma de planilha ou tabela, a metodologia costuma ser entregue em projetos, em reuniões para avaliar, e ter o acompanhamento a fim de garantir que tudo sejam feitas de forma certa e com excelência por todos os participantes durante o processo.

Segundo Barbosa et al. (2016, p. 29), o método utilizado 5W2H é útil na análise das situações em que há necessidade de verificar a ocorrência de um defeito e no desenvolvimento de um propósito de ação.

A ferramenta 5W2H são várias de questões utilizadas para compor planos de ação de maneira rápida e eficiente.

Seu principal objetivo é a definição de tarefas eficazes e sua vistoria, de maneira ágil e simples.

RC: 84989

Disponível em: https://www.nucleodoconhecimento.com.br/administracao/melhoria-da-area 
Segundo Custodio (2015, p. 32), 5W2H define um conjunto de perguntas, para melhor eficácia da solução de um problema esta técnica tem por finalidade simplificar o entendimento para a solução de problemas identificando onde deve ser trabalhado.

\section{MATERIAIS E MÉTODOS}

Metodologia é a área onde se estuda todas as possibilidades de métodos que possam ser utilizados no desenvolvimento de conhecimento aplicado à pesquisa científica, onde se terá estudos de caráter lógico e racional.

Segundo Lakatos e Marconi (2021), o tópico Material e Métodos pode também instruir o leitor a compreender melhor os resultados adquiridos, pois métodos diferentes de adquirir informações podem ocasionar em medidas ou amplitudes diferentes. Alguns procedimentos também podem ter sido sugestionados pelo procedimento implantado durante a pesquisa.

Desta forma este trabalho buscará meios de solucionar problemas através de métodos e ferramentas científicas que se igualem às necessidades da empresa.

\subsection{PROCEDIMENTOS METODOLÓGICOS}

A pesquisa apresentada é de caráter exploratório e qualitativo. A pesquisa foi realizada em uma empresa voltada para serviços de remoção de entulhos e dejetos de construção civil.

Os procedimentos foram realizados e voltados para a área mais crítica e com necessidade de desenvolvimento após uma análise de relatório feita nas visitas técnicas com a proprietária da empresa e colaboradores, a análise apontou que o ponto a se investir é no operacional e com isso desenvolver positivamente os seus serviços.

RC: 84989

Disponível em: https://www.nucleodoconhecimento.com.br/administracao/melhoria-da-area 


\subsubsection{QUANTO À NATUREZA}

A pesquisa qualificatória busca compreender questões humanas, adquirindo deles obter uma perspectiva detalhada fazendo uma análise científica .

Esta pesquisa se atenta com o significado dos acontecimentos e situações sociais. (KNECHTEL, 2014, p. 85).

A Pesquisa é baseada em análises detalhadas, que foi elaborada com coleta de dados, em visitas à empresa onde se destacou a importância da mudança da qualidade dos serviços.

Sendo a qualidade proveniente da capacidade de ofertar um trabalho de excelência e, para tal, se tem a obrigação de desenvolvimento relacionado com as áreas críticas a serem abordadas. O foco principal em termos qualitativos se dá ao fator social humano e com uma complexidade de comportamentos e resultados, se destacando a imprevisibilidade dos participantes da empresa.

\subsubsection{QUANTO AOS FINS}

Segundo Vergara (2015, p. 76), 'Uma pesquisa Exploratória é feita em áreas de pouco conhecimento adquirido, assim sendo não comporta ideias na sua fase inicial, porém no andamento da pesquisa estas poderão surgir naturalmente."

Quanto aos fins, a pesquisa está interessada na questão exploratória com o foco na questão dos serviços com a proposta de elevar o seu entendimento sobre como melhorar e desenvolver seus serviços de coleta de resíduos sólidos para maior contentamento dos seus compradores.

Essa finalidade tem como base as estruturas das pesquisas realizadas cujo resultado apontou uma necessidade de desenvolver este setor da empresa.

RC: 84989

Disponível em: https://www.nucleodoconhecimento.com.br/administracao/melhoria-da-area 


\subsubsection{QUANTO AOS MEIOS}

Segundo Köche (2015, p. 122), a análise quanto aos meios "Se mostra tentando identificar e resolver uma adversidade, utilizando o entendimento disponível a partir dos conceitos publicados em livros ou em trabalhos".

Portanto foi utilizado como embasamento uma série de teorias baseadas em autores voltados para a questão estudada com a pretensão de dar uma base mais sólida para o artigo.

\subsection{CARACTERÍSTICAS DA EMPRESA}

A empresa J.A. OLIVEIRA. PEIXOTO - ME foi fundada em 1987 passando por várias transformações ao vasto período, atuando no mercado com o nome fantasia de Repe Entulho há mais de uma década visando o desenvolvimento sustentável, vem estabelecendo parcerias importantes com companhias que trabalham em diversos segmentos, buscando resultados que contribuam com o crescimento e evolução. É uma empresa em busca da superação das expectativas de nossos colaboradores e clientes.

A empresa atualmente disponibiliza maquinários e equipamentos destinados à construção civil, e tem como intuito oferecer para seus clientes qualidade e comodidade.

Apesar de existir vários modelos e marcas, a empresa optou por trabalhar com sua própria marca, já reconhecida no mercado para assim proporcionar ao freguês um serviço satisfatório.

\section{RESULTADOS E DISCUSSÕES}

\subsection{GRÁFICO DAS ÁREAS CRÍTICAS}

RC: 84989

Disponível em: https://www.nucleodoconhecimento.com.br/administracao/melhoria-da-area 
Com base nas avaliações realizadas nas etapas do Diagnóstico Organizacional diagnosticamos certos pontos críticos nos quais podemos ter uma breve análise no gráfico 01 abaixo:

Gráfico 01: Média-Desempenho por Área Funcional

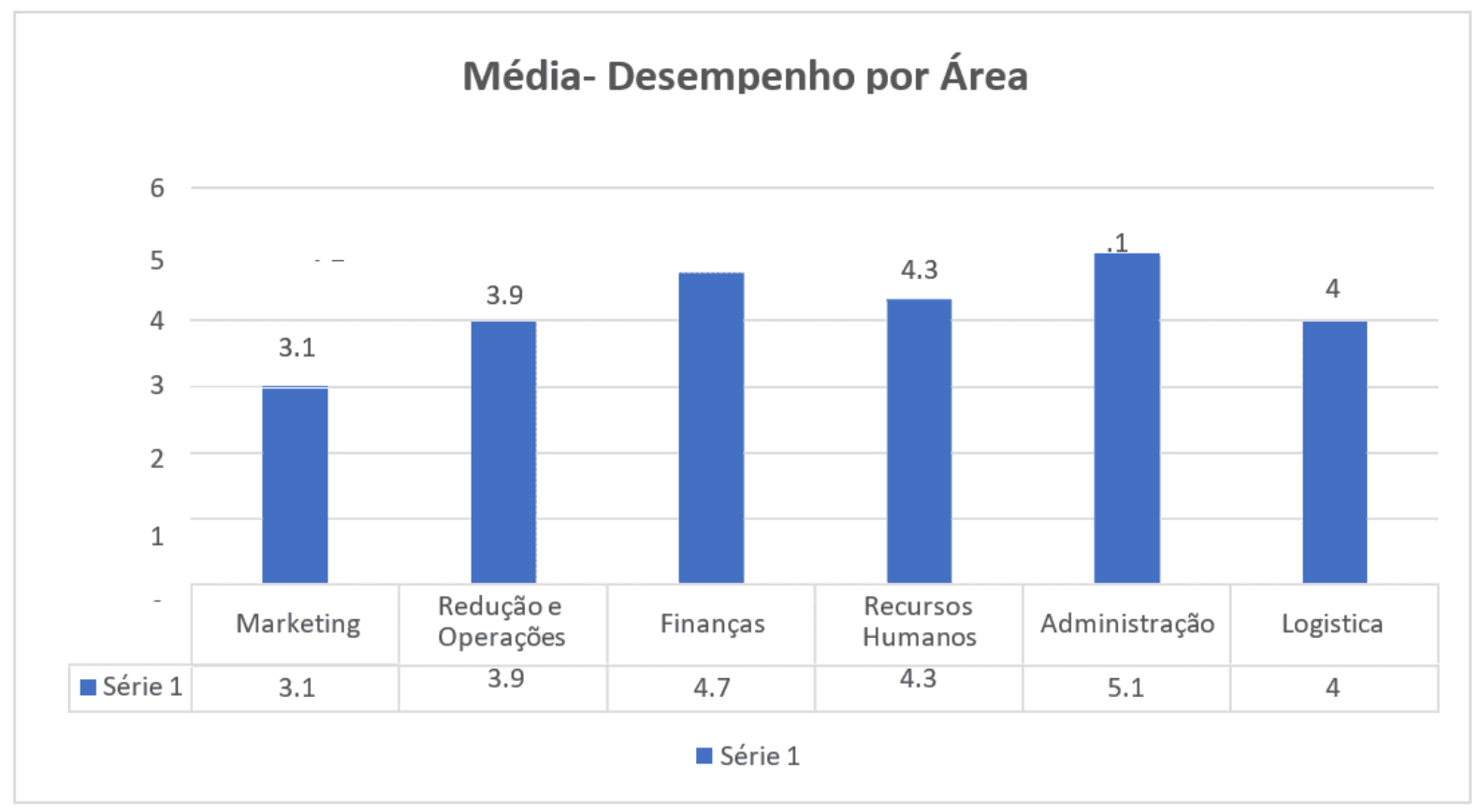

Fonte: Elaborado pelos autores, 2020.

De acordo com a pesquisa realizada na empresa J A OLIVEIRA PEIXOTO - ME. como mostra o gráfico de medição de desempenho o ponto mais crítico da empresa é o de marketing com uma média de 3.1 de desempenho, sendo os pontos mais fracos, a localização da empresa que se encontra muito afastada das regiões centrais da cidade, dificultando a logística para outras áreas, outro ponto fraco detectado foi de sua publicidade, que mesmo com serviço pago de divulgação na internet ainda possui pouca visibilidade.

O objetivo básico do marketing é a construção e a manutenção de relacionamentos lucrativos com os clientes numa perspectiva de longo prazo, ou seja, desenvolver RC: 84989

Disponível em: https://www.nucleodoconhecimento.com.br/administracao/melhoria-da-area 
uma base com os clientes, que fiquem comprometidos e que sejam rentáveis para a organização, quanto satisfatórios para os clientes, reter clientes representa desenvolver uma sólida e previsível base financeira para o futuro das atividades empresariais

Desta forma conseguimos montar um quadro de ações interventivas no qual conseguiremos resolver os problemas relacionados ao serviço de marketing e mediante a falta de visibilidade da empresa diante dos clientes e de possíveis venda em potencial.

Com a implantação das melhorias, a nossa pergunta problema foi, (Como o aprimoramento da qualidade de serviços pode contribuir com estratégias de marketing de serviços?), terá um desfecho positivo dentro do âmbito da empresa, com lucros, visibilidade e qualidade e até satisfação com nossos clientes.

Quadro 01: Area Funcional (Marketing)



RC: 84989

Disponível em: https://www.nucleodoconhecimento.com.br/administracao/melhoria-da-area 


\begin{tabular}{|c|c|c|c|c|c|c|}
\hline & serviços & & & & & \\
\hline 3 & Variedade de serviços & & & $x$ & & \\
\hline 4 & $\begin{array}{l}\text { Há empresa possui } \\
\text { preços competitivos com o } \\
\text { mercado }\end{array}$ & & $x$ & & & \\
\hline 5 & $\begin{array}{l}\text { O local onde a empresa se } \\
\text { encontra favorece a melhoria } \\
\text { das vendas }\end{array}$ & & & & $x$ & \\
\hline 6 & $\begin{array}{l}\text { Há organização possui } \\
\text { estratégias } \\
\text { de comunicação visual }\end{array}$ & & & $x$ & & \\
\hline 7 & $\begin{array}{l}\text { Há organização possuem } \\
\text { métodos de visualização dos } \\
\text { produtos e serviços }\end{array}$ & & & $x$ & & \\
\hline 8 & $\begin{array}{l}\text { Produtos sofisticados e variados } \\
\text { conforme pedido }\end{array}$ & & & $x$ & & \\
\hline 9 & $\begin{array}{l}\text { Há organização possui políticas } \\
\text { qualificadas de obtenção de } \\
\text { clientes }\end{array}$ & & & $x$ & & \\
\hline 10 & Visibilidade da organização & & & $x$ & & \\
\hline \multicolumn{2}{|c|}{ Total $(\Sigma)$} & 0 & 8 & 21 & 2 & 0 \\
\hline \multicolumn{2}{|c|}{ Média para o Grau (Por Coluna) } & 0 & 0.8 & 2.1 & 0.2 & 0 \\
\hline \multicolumn{2}{|c|}{ Desempenho da Area $(\Sigma)$ Total } & \multicolumn{5}{|l|}{3.1} \\
\hline
\end{tabular}

Fonte: Elaborado pelos autores, 2020.

No quadro 01, temos a área de marketing com suas respectivas áreas e condições de execução, tornando o marketing uma das principais ferramentas de adesão de RC: 84989

Disponível em: https://www.nucleodoconhecimento.com.br/administracao/melhoria-da-area 
mercado e nicho de clientes com a organização de suas metas em relação aos concorrentes, e como fazer para aperfeiçoar sua relação com o cliente aprimorando sua qualidade de seu serviço e manter a confiança dos clientes.

\subsection{QUADRO DE AÇÕES INTERVENTIVAS}

Estas ações consistem em mudanças para alcançar objetivos prósperos mediante ao mercado de Coleta e Reciclagem de Entulhos, contudo estes objetivos são propostos aos superiores para suas análises e aceitações de suas implantações.

Quadro 02: Ações Interventivas

\section{AÇÕES INTERVENTIVAS}

\begin{tabular}{|c|c|c|c|c|}
\hline ITEM & Ação Interventiva & Implantação & Cronograma & Custo/Valor \\
\hline 1 & $\begin{array}{l}\text { Aplicar } \\
\text { Treinamento Sobre } \\
\text { Padrões de Atendimento com } \\
5 \mathrm{w} 2 \mathrm{~h}\end{array}$ & mai/21 & 7 dias & $\mathrm{R} \$ 1.000,00$ \\
\hline 2 & $\begin{array}{l}\text { Aplicar melhorias de } \\
\text { Flexibilidade nos serviços aos } \\
\text { clientes }\end{array}$ & mai/21 & 15 dias & $R \$ 3.000,00$ \\
\hline 3 & $\begin{array}{l}\text { Implantar Melhores Preços e } \\
\text { Promoções }\end{array}$ & $a b r / 21$ & 5 dias & $R \$ 3.000,00$ \\
\hline 4 & $\begin{array}{l}\text { Implantação de Ferramenta } \\
\text { NPS para Melhorar } \\
\text { Atendimento ao Cliente }\end{array}$ & mai/21 & 8 dias & $R \$ 1000,00$ \\
\hline
\end{tabular}

RC: 84989

Disponível em: https://www.nucleodoconhecimento.com.br/administracao/melhoria-da-area 


\begin{tabular}{|l|l|l|l|l|l|}
\hline 5 & $\begin{array}{l}\text { Implantar Divulgação dos } \\
\text { Produtos e da Marca aos } \\
\text { Clientes }\end{array}$ & abr/21 & 10 dias & $\mathrm{R} \$ 3.000,00$ \\
\hline 6 & \begin{tabular}{l} 
Total \\
\hline
\end{tabular} & 37 dias & $\mathrm{R} \$ 8.030,00$ \\
\hline
\end{tabular}

Fonte: Elaborado pelos autores, 2020.

No quadro 02 , temos o quadro de ações interventivas que registra todas as ações a serem implantadas com suas datas, cronogramas e valores de custo, onde se tem um detalhamento das ações a serem concluídas como por exemplo aplicar um treinamento sobre padrões de atendimento com o 5w2h.

\section{IMPLANTAÇÃO DA FERRAMENTA DE QUALIDADE 5w2h}

Nossa proposta por meio dessas ações interventivas é a melhoria do sistema visando tanto o lucro para empresa quanto sua divulgação de sua marca para o comércio, tendo assim uma maior visibilidade, contudo vimos que para melhor análise utilizamos a ferramenta de qualidade $5 \mathrm{w} 2 \mathrm{~h}$ que nos proporciona os motivos desta implantação.

O 5W2H é uma técnica de fácil aplicação, onde é possível diagnosticar atividades e responsabilidades dentro de um esquema de ação permitindo a supervisão e o andamento dos trabalhos, o relatório conta as seguintes informações: What (O que deve ser feito Por que foi decidido esta solução?), Who (Quem será o responsável pelo início do procedimento?), When (Em que momento será o início?), Where (Qual o local da implantação?), Why (Porque deve ser executado essa implantação?), How (Como a ação vai ser inserida?) e How Much (Quanto será o valor para melhoria?).

RC: 84989

Disponível em: https://www.nucleodoconhecimento.com.br/administracao/melhoria-da-area 


\subsection{APLICAR TREINAMENTO SOBRE PADRÕES DE ATENDIMENTO COM 5W2H}

Primeiramente, ela é um dos pilares para o sucesso da Organização, ou seja, para melhorar essa consulta é fundamental montar estratégias de apoio e atendimento ao consumidor.

Logo, instituir o contentamento do cliente é de grande importância e para tornar o cliente um divulgador da sua marca. Sendo assim, ele poderá indicar a sua marca para outros clientes em potencial.

Entretanto, um bom atendimento pode ajudar diariamente para a fidelização do cliente, destacando sua empresa dos concorrentes e alavancar suas vendas.

Quadro 03: 5w2h- Aplicar Treinamento sobre padrões de Atendimento

\section{Aplicar Treinamento sobre padrões de Atendimento}

O que? $\quad$ Treinamento aos Colaboradores em Geral sobre relações humanas

Por quê? Padronização de Métodos e Conceitos

Onde? Empresa REPE ENTULHO

Quando? No mês de Maio de 2021

Quem? Recepção e Colaboradores em geral

Como? Empresa de implantação de curso de Relações Humanas (Estácio)

Quanto? $R \$ 1.000,00$

Fonte: Elaborado pelos autores, 2020.

No quadro 03 , temos como o detalhamento de como aplicar o treinamento sobre padrões de atendimento se utilizando da ferramenta $5 \mathrm{w} 2 \mathrm{~h}$ e suas descrições detalhadas de todo o processo e das formas a serem implantadas desde o que fazer, porque fazer e até quanto irá custar este processo de modificação.

$\mathrm{RC}: 84989$

Disponível em: https://www.nucleodoconhecimento.com.br/administracao/melhoria-da-area 


\subsection{APLICAR MELHORIAS DE FLEXIBILIDADE NOS SERVIÇOS AOS CLIENTES}

O comércio de trabalho hoje em dia está em contínuo procedimento de mudanças e transformações, que ocorrem para que haja atualização contínua, e não só para companhia e colaboradores, entretanto para os consumidores, que estão constantemente em busca de algo inovador e criativo para sanar seus prazeres materiais momentâneos.

Entende-se como liberdade no local de trabalho a agilidade que o profissional tem de se ambientar nas mais diferentes áreas, adaptando-se, com maior facilidade e rapidez, com estes novos desafios.

Além disso, são colaboradores que têm facilidade a novos processos, à mudanças de função e de cidades, que buscam desafios constantemente, e que têm saber multidisciplinar, algo que Ihes permite conhecer e atender às novas demandas da era digital que estamos vivendo.

Quadro 04: 5w2h- Aplicar melhorias de Flexibilidade nos serviços dos clientes

\section{Aplicar melhorias de Flexibilidade nos serviços aos clientes}

O que? Melhoria de tempo de serviços e agilidade na resposta

Por quê? Para ter a capacidade de atendimento de novas demandas do mercado

Onde? Empresa REPE ENTULHO

Quando? No mês de Maio de 2021

Quem? Todos os colaboradores incluindo os líderes e gerentes

Como? Será aplicado pela empresa SER.

Quanto? $\mathrm{R} \$ 3.000,00$

Fonte: Elaborado pelos autores, 2020.

$\mathrm{RC}: 84989$

Disponível em: https://www.nucleodoconhecimento.com.br/administracao/melhoria-da-area 
No quadro 04, temos a mesma ferramenta, porém, voltada para melhoria de flexibilidade nos serviços aos clientes, pois esse ponto é de bastante importância já que o mercado precisa entender as necessidades únicas de cada cliente, sendo aplicada na empresa REPE ENTULHO pela empresa SER incluindo toda a ajuda de seus colaboradores e administradores.

\subsection{IMPLANTAR MELHORES PREÇOS E PROMOÇÕES}

Ao analisarmos a resposta da Administradora, as promoções e preços fazem parte da estratégia da empresa, pois ela utiliza de imagens, apela para as emoções, traz informações de forma confiável e de qualidade e essa estratégia aplicada com o objetivo de alcançar muitos clientes possíveis. Conforme Torres (2018, p. 70), o cliente ou o curioso fica feliz porque recebe publicidade que é do seu interesse e o anunciante consegue atingir quem deseja tendo um retorno muito melhor do seu investimento.

Quadro 05: 5w2h- Implantar Melhores Preços e Promoções

\section{Implantar Melhores Preços e Promoções}

O que? Divulgação e MKT dos produtos e serviços nas mídias em geral

Por quê? Para uma melhor divulgação de seus produtos e serviços

Onde? Empresa REPE ENTULHO

Quando? No mês de Abril de 2021

Quem Implantação feita pela Empresa, Cursos IPED

Fazendo uma análise de mercado sobre preços e promoções e qual o

Como? impacto

positivo para empresa

Quanto? R\$3000,00

Fonte: Elaborado pelos autores, 2020.

RC: 84989

Disponível em: https://www.nucleodoconhecimento.com.br/administracao/melhoria-da-area 
No quadro 05, temos a Divulgação e MKT dos produtos e serviços nas mídias em geral, como se detectou uma necessidade de melhoramento deste quesito para uma melhor divulgação de seus serviços pois em um mercado competitivo a visibilidade de sua empresa consta como um dos principais fatores de diferença na hora de alcançar os clientes.

\subsection{IMPLANTAÇÃO DE FERRAMENTA NPS PARA MELHORAR ATENDIMENTO AO CLIENTE}

Melhorar o atendimento ao cliente é um processo. Começando do pressuposto que não consegue fazer essa mudança repentinamente, o certo é implantar atividades e procedimentos para facilitar e tornar mais prático o atendimento. No entanto, um procedimento de melhorar o atendimento ao consumidor é implantar práticas que o ajudam a fidelizar seus procedimentos. E, por consequência, a ter mais robustez no que for entregue.

Por isso, recomendam ferramentas de Net Promoter Score (NPS), que ajudam sua organização a contar com feedbacks contínuos de forma simplificada. E de com este sistema de Customer Relationship Management (CRM), imprescindíveis para que você salve as informações em nuvem.

Quadro 06: 5w2h- Implantação de Ferramenta para melhorar o atendimento ao cliente

\section{Implantação de Ferramenta NPS para melhorar atendimento ao cliente}

O que? Ferramentas NPS de melhoria ao atendimento

Por quê? Para melhoria e conscientização tantos dos clientes quanto dos funcionários

Onde? Empresa REPE ENTULHO

Quando? No mês de Maio de 2021

RC: 84989

Disponível em: https://www.nucleodoconhecimento.com.br/administracao/melhoria-da-area 
Quem? Empresa qualificada para de implantação de ferramenta NPS

Como? Empresa REPE ENTULHO (Computadores)

Quanto? R\$3.000,00

Fonte: Elaborado pelos autores, 2020.

No quadro 06, temos a avaliação NPS que consiste em avaliar a opinião dos clientes em relação a seus produtos e serviços, nesta avaliação constatou-se que a utilização de um sistema informatizado será de grande ajuda para avaliar a opinião de seus clientes de forma rápida e organizada.

\subsection{IMPLANTAR DIVULGAÇÃO DOS PRODUTOS E DA MARCA AOS CLIENTES}

Esta Implantação está em conjunto com a implementação de Melhores Preços e Promoções, pois as duas implantações juntas alavancam de todas as formas a empresa, tanto na parte financeira, MKT, econômica e também sua visibilidade no mercado melhora significativamente.

Outro ponto a ser analisado é o relacionamento com a imprensa, um bom relacionamento com jornalistas pode estabelecer um favorável nível de divulgação de maneira fácil e de certa forma com custo zero.

A internet viabiliza o marketing da marca, produtos, serviços, propaganda, publicidade, promoção e outros, e cada vez mais as organizações estão aceitando à internet como ferramenta na divulgação de comunicação e disseminação de informações, para poder manter uma interação mais curta com seus consumidores, por isso decidimos contratar a empresa theresultsengine.com para a implantação de melhoria e divulgação da marca e produtos aos clientes sobre coleta de reciclagem de entulhos e resíduos sólidos.

RC: 84989

Disponível em: https://www.nucleodoconhecimento.com.br/administracao/melhoria-da-area 
Quadro 07: 5w2h- Implantar Divulgação dos Produtos e da Marca aos Clientes

\section{Implantar Divulgação dos Produtos e da Marca aos Clientes}

O que? Divulgação da Marca e Produto para melhor visibilidade aos clientes Para melhoria tanto na busca de novos clientes como na firmação da marca no mercado.

Por quê?

Onde? Empresa REPE ENTULHO

Quando? No mês de Abril de 2021

Empresa qualificada para melhor planejamento e divulgação em

Quem?

Produtos e Marcas na Theresultsengine.com

Como? Em Salas de aulas com amostras de divulgações e pesquisas de mercado

Quanto? $\mathrm{R} \$ 3.000,00$

Fonte: Elaborado pelos autores, 2020.

No quadro 07 , temos a marca como o maior fator de reconhecimento no mercado principalmente com um valor agregado a esta marca, conclui-se que essa melhoria irá trazer tanto clientes novos como firmar a marca já existente, reforçando a confiança dos clientes que já conhecem o valor da empresa REPE ENTULHO.

\section{CONSIDERAÇÕES FINAIS}

Com as mudanças de mercado e a competitividade muito mais em evidência, as empresas devem estar em constante mudança e aprimoramento, neste sentido este artigo procurou elaborar uma ideia para a empresa estudada e com achar uma saída para o problema principal da empresa descoberto pela análise da pesquisa, e com a implementação das medidas cabíveis trouxe resultados de forma satisfatórias.

RC: 84989

Disponível em: https://www.nucleodoconhecimento.com.br/administracao/melhoria-da-area 
No âmbito geral quanto na pesquisa e resultado foi determinado o melhoramento dos seus serviços e que com a implementação gerará resultados positivos nas suas respectivas áreas que foram abordadas no decorrer deste trabalho, no que consta em questões específicas ouve primariamente o interesse de coletar dados referente a empresa como visitas técnicas, entrevistas com os funcionários e a gestão principal, para uma análise de sua condição, após isso foi feito alguns levantamentos dessas análises, informações em forma gráficos e tabelas como $5 \mathrm{w} 2 \mathrm{~h}$ onde ficou registrado de forma detalhada as condições atuais da companhia e suas necessidades de intervenção, tudo isso com orientações bibliográficas de obras renomadas na literatura científica.

A confirmação da hipótese da ação desenvolvida se deu por avaliar as condições de trabalho, e, qual o setor com alto índice de problemas ser mudado e por possuir fatores humanos foi confirmada a ação direta na questão de pessoal que está diretamente atrelado com trabalho dos colaboradores.

Este trabalho foi desenvolvido através de uma pesquisa bibliográfica e na companhia com coletas de informações com o objetivo de analisar as condições de serviço de uma companhia de coleta de resíduos sólidos com a análise dos interesses da organização com o foco nos seus serviços oferecidos e como isso pode ser desenvolvido para melhorar o vínculo com os seus clientes.

\section{REFERÊNCIAS}

AUGUSTO, A. S. Grêmio E Marketing 3.0: Análise De Matérias Sobre A Comunidade Tri Nos Portais De Notícias, setembro De 2015. Universidade Federal do Rio Grande do Sul. Porto Alegre, 2016.

BARBOSA, A. F. et al. Importance of Quality Management in the Processors of Fruit and Vegetable Industries. 2016.

RC: 84989

Disponível em: https://www.nucleodoconhecimento.com.br/administracao/melhoria-da-area 
CUSTÓDIO, M. F. Gestão da qualidade e produtividade. 2015. Pearson Education do Brasil. São Paulo, SP.

GIL, A. C. Como elaborar projetos de pesquisa. 6. ed. São Paulo: Atlas, 2017.

GOLLO, S. S. et al. Marketing sustentável para a melhoria da gestão de resíduos sólidos urbanos em município do Alto Uruguai Gaúcho, Estado do Rio Grande do Sul, Brasil. Rev. Bras. Gest. Amb. Sustent. [online]. 2019, vol. 6, n. 12, p. 175-195. ISSN 2359-1412.

KAWAMURA, D. N. C. A Evolução Do Marketing E O Impacto Sobre Os Consumidores Contemporâneos: Um Estudo De Caso Da Marca Dove. Instituto Municipal de Ensino Superior de Assis - IMESA. Fundação Educacional do Município de Assis - FEMA, Assis, 2015.

KNECHTEL, M. R. Metodologia da pesquisa em educação: uma abordagem teórico-prática dialogada. Curitiba: Intersaberes, 2014.

KÖCHE, J. C. Fundamentos de Metodologia Científica: Teoria da Ciência e Iniciação à Pesquisa. Petrópolis. Vozes. 2015.

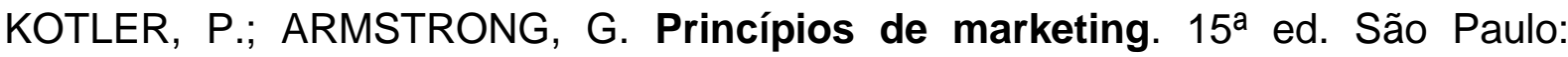
Pearson, 2015.

KOTLER, P. Marketing 4.0 - do Tradicional ao Digital (Livro eletrônico). New Jersey: John Wiley \& Sons, Inc., 2017.

LAKATOS, E. M.; MARCONI, M. A. Fundamentos de Metodologia Científica. Atlas; 9르 ed. 2021

MONTEIRO, A. H.; BARRETO, A. G. P. Marketing 4.0 e a Cultura de Fãs: Potterheads comprovam que, mais uma vez, Kotler está certo. Trabalho 
apresentado no XIX Congresso de Ciências da Comunicação na Região Nordeste, Fortaleza, 2017.

PRADO, I. O. Aplicação Do Marketing Sustentável Nas Empresas Brasileiras. Trabalho Apresentado no Encontro Internacional sobre Gestão Empresarial e Meio Ambiente. São Paulo, 2017.

SANTOS, F. A. Marketing na Era Digital: Análise da marca Chico Rei. UFJF. Juiz de Fora. 2014

SEIFRIED, T. M. A Importância Da Segmentação Na Publicidade: A Influência Do Google Como Mídia Na Internet. IJUÍ. 2014.

TORRES, C. A bíblia do marketing digital: tudo o que você queria saber sobre marketing e publicidade na internet e não tinha a quem perguntar. Novatec Editora, 2018.

VERGARA, S. C. Métodos de Pesquisa em Administração. 6ª Edição, 2015.

Enviado: Abril, 2021.

Aprovado: Maio, 2021.

RC: 84989 